\title{
Shock wave treatment induces angiogenesis and mobilizes endogenous CD31/CD34-positive endothelial cells in a hindlimb ischemia model: Implications for angiogenesis and vasculogenesis
}

\author{
Can Tepeköylü, MD, ${ }^{a}$ Feng-Sheng Wang, PhD, ${ }^{\text {,cc }}$ Radoslaw Kozaryn, MS, ${ }^{a}$ Karin Albrecht-Schgoer, PhD, ${ }^{\mathrm{d}}$ \\ Markus Theurl, MD, ${ }^{\mathrm{d}}$ Wolfgang Schaden, MD, ${ }^{\mathrm{e}}$ Huei-Jin Ke, ${ }^{\mathrm{b}}$ Yaju Yang, ${ }^{\mathrm{b}}$ Rudolf Kirchmair, MD, ${ }^{\mathrm{d}}$ \\ Michael Grimm, MD, ${ }^{\mathrm{a}}$ Ching-Jen Wang, MD, ${ }^{\mathrm{b}, \mathrm{c}}$ and Johannes Holfeld, $\mathrm{MD}^{\mathrm{a}}$
}

\begin{abstract}
Objectives: Shock waves have been shown to induce recruitment of intravenously injected endothelial progenitor cells to ischemic hind limbs in rats. We hypothesized that shock wave treatment as sole therapy would induce angiogenesis in this ischemia model and would lead to mobilization of endogenous endothelial (progenitor) cells.

Methods: A total of 18 rats, aged 5 weeks old, were subdivided into 3 groups: sham $(n=6)$, ischemic muscle with shock wave treatment (shock wave treatment group, $\mathrm{n}=6$ ), and without shock wave treatment (control, $\mathrm{n}=6$ ). Hind limb ischemia was induced by ligation of the femoral artery. Three weeks later, shock wave treatment (300 impulses at $0.1 \mathrm{~mJ} / \mathrm{mm}^{2}$ ) was applied to the adductor muscle; the controls were left untreated. Muscle samples were analyzed using real-time polymerase chain reaction for angiogenic factors and chemoattractants for endothelial progenitor cell mobilization. Fluorescence activated cell sorting analysis of the peripheral blood was performed for CD31/CD34-positive cells. Perfusion was measured using laser Doppler imaging. Functional improvement was evaluated by walking analysis.
\end{abstract}

\begin{abstract}
Results: Angiogenic factors/endothelial progenitor cell chemoattractants, stromal cell-derived factor-1 and vascular endothelial growth factor, were increased in the treatment group, as shown by real-time polymerase chain reaction, indicating the mobilization of endothelial progenitor cells. Fluorescence activated cell sorting analysis of the peripheral blood revealed high numbers of CD31/CD34-positive cells in the treatment group. Greater numbers of capillaries were found in the treated muscles. Blood perfusion increased markedly in the treatment group and led to functional restoration, as shown by the results from the walking analysis.
\end{abstract}

Conclusions: Shock wave therapy therefore could develop into a feasible alternative to stem cell therapy in regenerative medicine, in particular for ischemic heart and limb disease. (J Thorac Cardiovasc Surg 2013;146:971-8)

Shock wave therapy (SWT) causes relief of angina symptoms in patients with ischemic heart disease. ${ }^{1}$ Our group has shown that direct epicardial application of shock waves improves left ventricular function in chronic myocardial ischemia in rats. A significantly greater number of vessels and endothelial cells were found in the ischemic myocardium. ${ }^{2}$ Clear evidence is available of neovascularization after SWT. ${ }^{3,4}$ However, the origin of endothelial cells forming new vessels remains unknown. Whether the effect is by

\footnotetext{
From the Department of Cardiac Surgery, ${ }^{a}$ Innsbruck Medical University, Innsbruck, Austria; Department of Orthopedic Surgery, ${ }^{b}$ Chang Gung Memorial Hospital, Kaohsiung, Taiwan; Chang Gung University College of Medicine, ${ }^{\mathrm{c}}$ Kaohsiung, Taiwan; Department of Internal Medicine I, ${ }^{\mathrm{d}}$ Innsbruck Medical University, Innsbruck, Austria; and AUVA Trauma Center Meidling, ${ }^{\mathrm{e}}$ Vienna, Austria.

This work was supported in part by a research grant from Medizinischer Forschungsfonds Tirol, project no. 220 (to J.H.)

Disclosures: Authors have nothing to disclose with regard to commercial support.

Received for publication Sept 29, 2012; revisions received Dec 17, 2012; accepted for publication Jan 11, 2013; available ahead of print Feb 11, 2013.

Address for reprints: Johannes Holfeld, MD, Department of Cardiac Surgery, Innsbruck Medical University, Anichstr 35, Innsbruck 6020, Austria (E-mail: johannes.holfeld@uki.at).

0022-5223/\$36.00

Copyright (c) 2013 by The American Association for Thoracic Surgery

http://dx.doi.org/10.1016/j.jtcvs.2013.01.017
}

angiogenesis owing to the sprouting of existing vessels or by vasculogenesis with the recruitment of endogenous endothelial progenitor cells (EPCs) and subsequent new vessel formation has not been demonstrated.

Aicher and colleagues ${ }^{5}$ found enhanced recruitment of intravenously injected EPCs to shock wave-treated ischemic hind limbs in rats. Stromal cell-derived factor-1 (SDF-1), the main chemoattractant for the recruitment and homing of EPCs, was significantly upregulated in the treated muscle. Shock waves were applied 24 hours before cell injection as a preconditioning of the ischemic tissue. These results were confirmed by Yeh and colleagues. ${ }^{6}$

We therefore hypothesized that SWT stimulates angiogenesis and mobilizes endogenous EPCs without the necessity of any subsequent cell injection.

\section{METHODS \\ Animal Model}

The experiments were approved by the institutional animal care and use committee at Chang Gung Memorial Hospital. The investigation conformed to the "Guide for the Care and Use of Laboratory Animals" published by the US National Institutes of Health (NIH Publication No. 85-23, revised 1996; available from: www.nap.edu/catalog/5140.html). 


$$
\begin{aligned}
& \text { Abbreviations and Acronyms } \\
& \text { Ct }=\text { cycle threshold } \\
& \text { CTR }=\text { control } \\
& \text { EPC }=\text { endothelial progenitor cell } \\
& \text { HIF- } 1 \alpha=\text { hypoxia-inducible factor } 1 \alpha \\
& \text { PCNA }=\text { proliferating cell nuclear antigen } \\
& \text { SDF-1 }=\text { stromal cell-derived factor- } 1 \\
& \text { SWT }=\text { shock wave therapy } \\
& \text { VEGF }=\text { vascular endothelial growth factor }
\end{aligned}
$$

A total of 54, random, 5- to 6-week-old Sprague-Dawley rats (weight, 150$190 \mathrm{~g}$ ) were obtained from Charles River Technology (BioLASCO Taiwan, Taipei, Taiwan). During the experiments, the rats were housed under standard conditions with a 12-hour light/dark cycle. Water and a commercial rat diet were available ad libitum. The rats were randomly divided into 3 groups: the control group (CTR, $n=18$, hind limb ischemia without treatment), treatment group (SWT, $\mathrm{n}=18$, hind limb ischemia with SWT), and sham group ( $n=18$, sham surgery only). Next, 6 rats per group were anesthetized at 24 hours, 1 week, and 6 weeks after SWT. The whole adductor muscle was harvested and split in half into a proximal and distal portion. Of the distal portion, the middle part around the former femoral artery was used for analysis to avoid sampling variances of regions with greater or lesser ischemia.

A rat model of unilateral hind limb ischemia was performed in the treatment and control groups, as described previously. ${ }^{5}$ In brief, anesthesia was administered by an intraperitoneal injection of ketamine (Pfizer, New York, $\mathrm{NY} ; 100 \mathrm{mg} / \mathrm{kg}$ ) and xylazine (Rompun, Bayer, Germany; $10 \mathrm{mg} / \mathrm{kg}$ ). The proximal portion of the left femoral artery, including the superficial and deep branch, and the distal portion were occluded by a suture ligation. In the sham group, the adductor muscle was surgically exposed exactly as in the treatment and control rats. The sample size of each group at each measurement point was 6 .

\section{Shock Wave Treatment}

At 3 weeks after hind limb ischemia surgery, a single SWT was performed in the treatment group (SWT); the CTR group was left untreated. Anesthesia was given as described. The commercially available dermaPACE device (Sanuwave Health, Alpharetta, Ga) and an Orthogold device with applicator CG050-P (Tissue Regeneration Technologies, Woodstock, $\mathrm{Ga}$ ) were both used for SWT, delivering exactly the same treatment parameters. Both devices have been certified for human use. The following treatment parameters were derived from our experience in human application and could therefore be directly translated to the clinic. Thus, 300 impulses, at an energy flux density of $0.1 \mathrm{~mJ} / \mathrm{mm}^{2}$ and a frequency of $4 \mathrm{~Hz}$, were applied to skin at the area of the adductor muscle, translating to 4 impulses/s and less than 1.5 minutes overall treatment time. Common ultrasound gel was used for coupling the shock wave applicators.

\section{Real-Time Polymerase Chain Reaction}

Real-time polymerase chain reaction analysis was performed 24 hours and 6 weeks after treatment. One microgram of total RNA in muscle tissue extracted using QIAzol reagent (Qiagene, Valencia, Calif) was reverse transcribed. Complementary DNA equivalent 20 ng total RNA was mixed with $2 X$ iQ SYBR Green Supermix and specific primers and then polymerase chain reaction amplified by an iCycler iQ real-time polymerase chain reaction detection system (Bio-Rad Laboratories, Hercules, Calif). The following primer oligonucleotide sequences were used: $\beta$-actin, forward: 5'-TTG CTG ACA GGA TGC AGA AGG AGA-3'; reverse: $5^{\prime}$-ACT CCT GCT TGC TGA TCC ACA TCT-3'); vascular endothelial growth factor (VEGF)-A (forward: 5'-GCC CAT GAA GTG GTG AAG TT-3'; reverse: $5^{\prime}$-ACT CCA GGG CTT CAT CAT TG-3'); hypoxia-inducible factor- $1 \alpha$ (HIF- $1 \alpha$ ) (forward: $5^{\prime}$-GGC GGC GAG AAC GAG AAG-3'; reverse: $5^{\prime}$-GTG GCA ACT GAT GAG CAA GC-3'); SDF-1 forward: (5'-ATT CTT TGA GAG CCA TGT CGC CAG-3'; reverse: $5^{\prime}$-TCA TGG AAT TGA GTG CAT GCT GCG-3') and C-X-C chemokine receptor type 4 (forward: $5^{\prime}$-TCG TGC ACA AGT GGATCT CCATCA-3'; reverse: $5^{\prime}$-TCATGG AAT TGA GTG CAT GCT GCG-3'). The real-time polymerase chain reaction amplicons were sequenced (Center of Molecular Medicine, National Cheng Kong University, Taipei, Taiwan) and matched using the National Center Biotechnology Information Basic Local Alignment Search tool. The values of cycle threshold $(\mathrm{Ct})$ were computed at the beginning of logarithmic amplification of the reaction. The relative abundance of each gene, normalized to the housekeeping gene $\beta$-actin, was calculated as $2^{-\mathrm{DCt}}$, where $\mathrm{DCt}=\mathrm{Ct}_{\text {target gene }}-\mathrm{Ct}_{\beta \text {-actin }}$.

\section{VEGF Enzyme-Linked Immunosorbent Assay}

Muscle proteins were extracted by sonication in $500 \mu \mathrm{L}$ phosphatebuffered saline buffer. The VEGF concentrations were determined using a mouse VEGF enzyme-linked immunosorbent assay kit according to the protocol of the manufacturer (R\&D Systems Europe, Abingdon, United Kingdom). In brief, $50 \mu \mathrm{L}$ of assay diluents RD1N were added to each well of 96-well polystyrene microplates. Next, $50 \mu \mathrm{L}$ of the standard, control, or samples were added to each well, mixed by gently tapping the plate frame for 1 minute and incubated for 2 hours at room temperature. Thereafter, washing with wash buffer $(400 \mu \mathrm{L})$ was performed 5 times followed by addition of $100 \mu \mathrm{L}$ of mouse VEGF conjugate to each well, incubation for 2 hours at room temperature, and washing again with wash buffer 5 times. Subsequently, $100 \mu \mathrm{L}$ of substrate solution was added to each well and incubated for 30 minutes at room temperature. Finally, $100 \mu \mathrm{L}$ of stop solution was added to each well, and the concentration was determined with an enzyme-linked immunosorbent assay reader at $450 \mathrm{~nm}$. The VEGF protein concentration is given as $\mathrm{pg} / \mathrm{mg}$ protein (as determined using the bicinchoninic acid method).

\section{Immunohistochemistry}

Muscle tissue was taken from the adductor muscle at 24 hours and 6 weeks after treatment. The specimens were fixed in 3\% phosphate-buffered salinebuffered formaldehyde and embedded in paraffin, cut longitudinally into $4-\mu \mathrm{m}$ sections, and transferred to polylysine-coated slides. Serial sections were stained with hematoxylin and eosin, polyclonal anti-CD31 antibody (Abbiotec, San Diego, Calif), and a monoclonal antiproliferating cell nuclear antigen (PCNA) antibody (Millipore, Billerica, Mass). In brief, the deparaffinized sections were preincubated with $3 \%$ hydrogen peroxide and horse serum (Bio SB, Santa Barbara, Calif) to block endogenous peroxidase and antigen activity before incubation with the primary antibody (CD31, 1:50 dilution; PCNA 1:250 dilution). PolyDetector horseradish peroxidase$3^{\prime}$-, $3^{\prime}$-diaminobenzidine detection system (Bio SB) was used to detect positive staining. The distal half of the adductor muscle was divided into 3 parts, and 5 images from a section of each part were analyzed using a Zeiss Axioskop 2 plus microscope (Carl Zeiss, Munich, Germany). All images of each specimen were captured using a Cool charge-coupled device camera (SNAP-Pro $c f$ Digital Kit; Media Cybernetics, Rockville, Md). The images were analyzed using Image-Pro Plus image-analysis software (Media Cybernetics). The number of immunolabeled-positive cells and the total number of cells were counted. The results are expressed as the percentage of total cell number per high power field. Quantification analysis was performed by a researcher who was unaware of the treatment group.

\section{Flow Cytometry}

Before treatment and at 24 hours, 1 week, and 6 weeks after SWT, peripheral blood samples from the tail vein were obtained. Lysing buffer was added (Pharm Lyse, BD Biosciences, Franklin Lakes, NJ) and incubated with monoclonal mouse IgG to CD31 (eBioscience, San Diego, Calif) 
and polyclonal goat IgG to CD34 (R\&D Systems, Minneapolis, Minn). The cells were analyzed using flow cytometry with a FACSCalibur cell analyzer (BD Biosciences). The data were further processed using BD Cell Quest software (BD Biosciences). The results are expressed as the percentage of the total cell number.

\section{Blood Flow Measurement}

Blood flow measurements were performed using a laser Doppler perfusion image analyzer (moorLDLS, Moor Instruments, Devon, UK), as previously reported. ${ }^{7}$ To minimize the data variables attributable to ambient light and temperature, the rats were kept on a heating plate at $37^{\circ} \mathrm{C}$ before measurement, and blood perfusion was expressed as the laser Doppler perfusion image index representing the ratio of right (operated, ischemic leg) versus left (not operated, nonischemic leg) limb blood flow. A ratio of 1 before surgery indicated equal blood perfusion in both legs.

\section{Walking Analysis}

The CatWalk gait analysis (Noldus CatWalk XT 8.0, Wageningen, The Netherlands) was performed, as previously reported. ${ }^{8}$ In brief, the rats crossed a horizontal glass runway equipped with a standard chargecoupled device camera connected to a personal computer with the CatWalk software. The rats were tested before SWT and 1 and 6 weeks after SWT. Every rat had to cross the walkway without any interruption or hitch. For each rat, a minimum of 3 correct crossings was required. ${ }^{9}$

\section{Statistical Analysis}

All results are expressed as the mean \pm standard error of the mean. Statistical comparisons between the 2 groups were performed using Student's $t$ test. Continuous variables were either compared using analysis of variance (Bonferroni) after testing for normality of the distribution or the MannWhitney $U$ test.

\section{RESULTS}

\section{Increase of Circulating EPCs in Peripheral Blood}

Flow cytometry of the peripheral blood showed no difference in the circulating CD31- or CD34-positive cells between groups before treatment (percentage of total cell number, SWT, $5.03 \% \pm 0.43 \%$; CTR, $5.11 \% \pm 0.42 \%$; sham, $5.50 \% \pm 0.57 \%$ ). After 24 hours, significantly greater numbers were found in the SWT group than in the untreated controls (SWT, $10.61 \pm 0.86$ vs CTR, $5.4 \pm 0.42, P=.005$; sham, $4.59 \pm 0.38$ ). At 1 week after treatment, the number of circulating progenitor cells was still elevated in the treatment group (SWT, $8.32 \pm 1.73$ vs CTR, $5.15 \pm 0.54$, $P=.16$; sham, $4.47 \pm 0.66$ ). However, after 6 weeks, no difference between the treatment and control rats was observed (SWT, $3.78 \pm 0.63$ vs CTR, $2.53 \pm 0.73, P=.11$; sham, $4.49 \pm 0.91$; Figure 1). The elevation of circulating EPCs during the study period indicated an early mobilization of EPCs by SWT, peaking after 24 hours. After 1 week, a nonsignificant elevation was still observed.

\section{Increase of Angiogenic and Chemoattractive Factors in Treated Muscle}

HIF- $1 \alpha$ plays a crucial role in the regulation of SDF-1. SDF-1 itself serves as 1 of the most potent chemoattractants for recruitment of EPCs from bone marrow. ${ }^{10}$ Significantly increased mRNA levels (expressed in arbitrary units) of HIF- $1 \alpha$ (24 hours, SWT, $114.11 \pm 25.15$ vs CTR, $39.98 \pm 1.36, P=.047$; sham, $91.67 \pm 6.08$; 6 weeks, SWT, $103.99 \pm 7.60$ vs CTR, $69.10 \pm 5.44, P=.005$; sham, $105.48 \pm 29.37)$ and SDF-1 (24 hours, SWT, $140 \pm 17.98$ vs CTR, $47.46 \pm 10.32, P=.03$; sham, $144.46 \pm 48.71 ; 6$ weeks, SWT, $111.44 \pm 13.15$ vs CTR, $61.17 \pm 9.12, P=.02$; sham $74.00 \pm 12.49$ ) were found in treated muscles compared with the untreated controls (Figure 2, $A$ and $B$ ). At the same time, the SDF-1 receptor C-X-C chemokine receptor type 4 was upregulated significantly (24 hours, SWT, $709 \pm 78.75$ vs CTR, $220.88 \pm 53.24, P=.01$; sham, $97.91 \pm 10.06$; 6 weeks, SWT, $40.67 \pm 2.13$ vs CTR, $27.53 \pm 6.05, P=.03$; sham, $45.95 \pm 13.79$; Figure 2, C). VEGF-A was upregulated in the treatment and control group 24 hours after SWT (SWT, $297.32 \pm 60.89$ vs CTR, $313.99 \pm 51.64, P=.45$; sham, $126.17 \pm 24.90$ vs CTR, $P=.06$; sham vs SWT, $P=.17$ ). However, in the treatment group, VEGF was still elevated 6 weeks after treatment (SWT, $216.51 \pm 37.38$ vs CTR, $128.17 \pm 13.54, P=.0497$; sham, $159.39 \pm 23.30$; Figure $2, D$ ). The VEGF protein concentration (given as pg/ mg protein) confirmed this finding, with a significant increase in the treatment group compared with the untreated controls (SWT, $167.50 \pm 0.71$ vs CTR, $124.33 \pm 16.07, P=.037$; Figure 2,E). VEGF is well known, not only as the pivotal angiogenic growth factor, but also for its major chemoattractive effect toward EPCs. ${ }^{11,12}$ No significant differences within the sham groups at 24 hours and 6 weeks of follow-up were observed in any of the analyses.

\section{Increase of Capillary Density in Treated Ischemic Muscles}

Immunohistochemical staining for CD31-positive cells revealed significantly greater numbers of capillaries at 24 hours (SWT, $51.86 \pm 4.86$ vs CTR $25.15 \pm 6.66$, $P=.009$; sham, $41.58 \pm 6.61$ ) and 6 weeks (SWT, $66.48 \pm 4.67$ vs CTR, $43.82 \pm 5.47, P=.02$; sham, $39.25 \pm 7.34$ ) after SWT (Figure 3, $A$ and $C$ ). The data are expressed as the percentage of total cells per high power field.

Significantly greater numbers of proliferating cells, probably representing endothelial cells from histologic localization, were found in the treatment group, as shown by PCNA staining (24 hours, SWT, $43.15 \pm 5.88$ vs CTR, $24.59 \pm 2.62$, $P=.0007$; sham, $23.03 \pm 2.47 ; 6$ weeks, SWT, $41.41 \pm 2.62$ vs CTR, $31.10 \pm 2.62, P=.02$; sham, $26.74 \pm 2.62$; Figure 3 , $B$ and $C$ ). Because no double-staining was performed (PCNA and CD31), a part of these cells might also have represented other cell types. These data indicate that in addition to mobilization of EPCs, SWT also stimulates local angiogenesis in the ischemic muscle.

\section{Restoration of Blood Perfusion}

Blood perfusion of the hind limbs was measured using laser Doppler perfusion imaging 6 weeks after treatment 

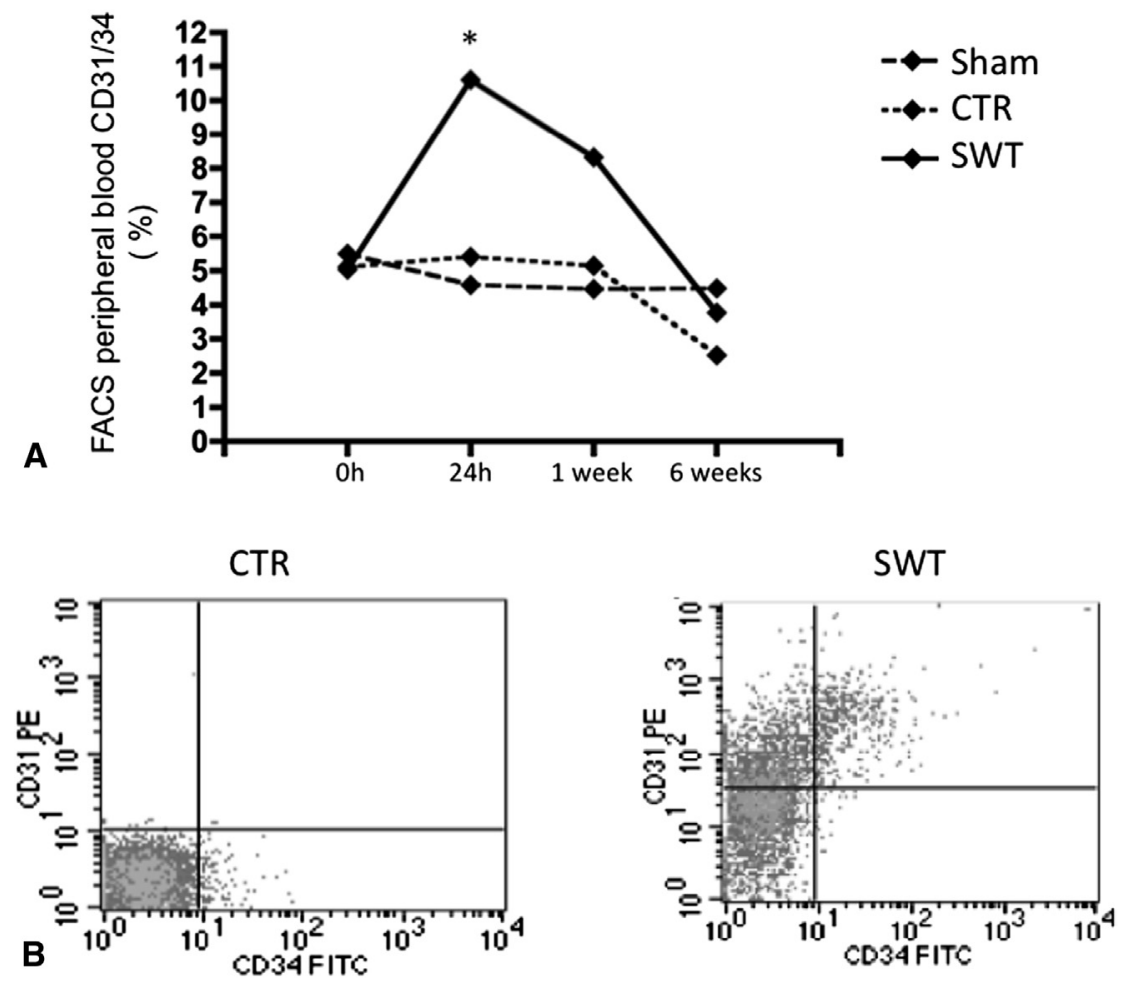

FIGURE 1. Circulating CD31/CD34-positive endothelial cells. A, Fluorescence activated cell sorting (FACS) analysis of peripheral blood revealed significantly greater numbers of circulating CD31/CD34-positive endothelial cells 24 hours after shock wave treatment (SWT), indicating early mobilization of endothelial progenitor cell, most probably from bone marrow. Number of endothelial progenitor cells still elevated after 1 week; however, 6 weeks after SWT, no difference found between treatment and control (CTR) group. $* P<.05$. B, Representative views from fluorescence activated cell sorting 24 hours after SWT showing greater numbers of endothelial progenitor cells in treatment group. FITC, Fluorescein isothiocyanate.

(Figure 4, $A-C$ ). Significant improvement was observed in the treatment group (SWT, $1.06 \pm 0.02$ vs CTR, $0.81 \pm 0.04, P=.003$; sham $1.01 \pm 0.07)$. Data are expressed as the ratio of the left (operated, ischemic) to right (control, nonischemic) leg (Figure 4,D).

\section{Functional Recovery of Ischemic Limbs}

Functional assessment was performed using catwalk gait analysis 6 weeks after treatment. The functional assessment showed that restored blood perfusion resulted in recovery of the walking pattern in the SWT rats. Significant improvement was found in the swing speed of the hind limbs (SWT, $961.66 \pm 36.64 \mathrm{~mm} / \mathrm{s}$ vs CTR, $749 \pm 41.47 \mathrm{~mm} / \mathrm{s}$, $P=.002$; sham, $859.19 \pm 98.1 \mathrm{~mm} / \mathrm{s}$ ) and in their maximum print intensity (arbitrary units; SWT, $218.02 \pm 3.58$ vs CTR, $202.29 \pm 8.84, P=.047$; sham, $216.36 \pm 2.84$; Figure 5, $A$ and $B$ ). Moreover, recovery was seen in the mean stride length (SWT, $148.36 \pm 1.97 \mathrm{~mm}$ vs CTR, $96.44 \pm 15.22 \mathrm{~mm}, P=.02$; sham, $114.59 \pm 13.09 \mathrm{~mm}$ ) and mean print area (SWT, $131.33 \pm 26.83 \mathrm{~mm}^{2}$ vs CTR, $82.33 \pm 16.36 \mathrm{~mm}^{2}, P=.045$; sham, $249.86 \pm 82 \mathrm{~mm}^{2}$; Figure $5, C$ - $E$ ). Figure $5, F$ shows the walking pattern of an untreated control and that of a SWT rat, clearly depicting the restoration in walking regularity.

\section{DISCUSSION}

SWT was shown to enhance recruitment of intravenously injected EPCs to ischemic muscle in rats. ${ }^{5,6}$ Although the combination of EPC injection and SWT showed promising results, SWT alone would cause less side effects in a clinical setting than would any type of cell therapy.

In the present study, we, therefore, hypothesized that upregulation of chemokines SDF-1 and VEGF after SWT would also lead to mobilization of endogenous circulating endothelial cells eligible for vasculogenesis. ${ }^{13}$

Thus, we created a model of chronic hind limb ischemia in rats. SWT was applied 3 weeks after ligation of the femoral artery.

Real-time polymerase chain reaction analysis of SDF-1 showed significantly greater levels in the muscle of the treatment group than in those of the untreated controls. Hence, at 24 hours after treatment, fluorescence activated cell sorting analysis of the peripheral blood revealed significantly increased numbers of circulating CD31/CD34positive EPCs.

In line with these findings, we found a greater density of CD31-positive capillaries in the ischemic muscle tissue 6 weeks after treatment. Together with our findings of EPC 
HIF-1 $\alpha$

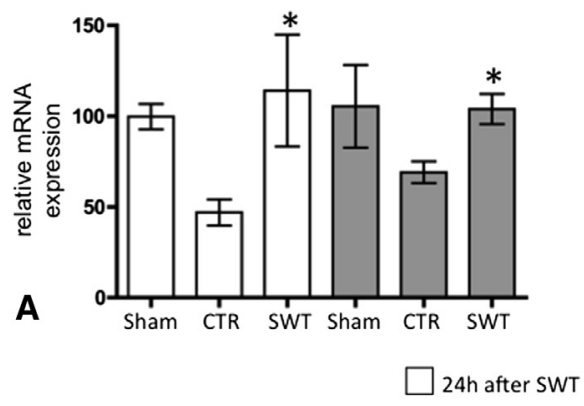

SDF-1

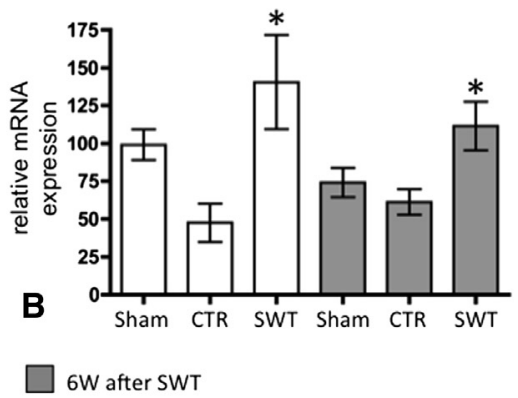

VEGF-A

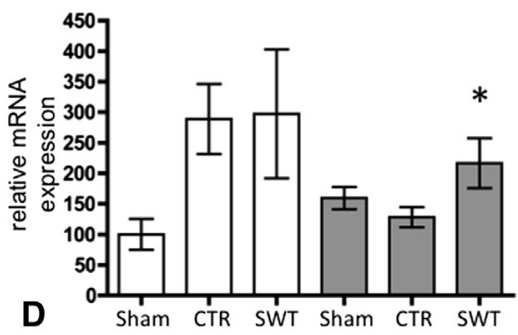

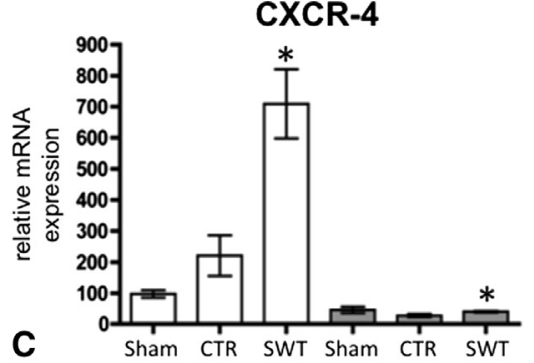

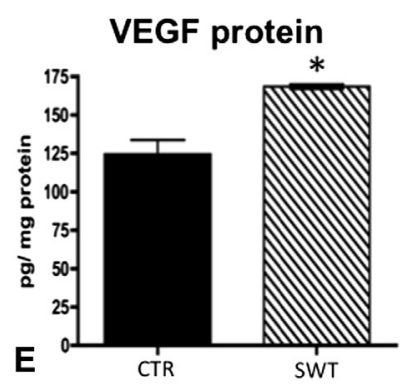

FIGURE 2. Increase of angiogenic and chemoattractive factors in treated muscle. A, Expression of hypoxia-inducible factor $1 \alpha(H I F-1 \alpha)$ regulating stromal cell-derived factor-1 (SDF-1) significantly elevated in treatment group 24 hours and 6 weeks after shock wave therapy (SWT). In line with these findings, $\mathrm{B}$, SDF-1 and C, its receptor C-X-C chemokine receptor type 4 (CXCR-4) also significantly upregulated. Vascular endothelial growth factor (VEGF)-A mRNA showed increased levels at 24 hours after treatment in treatment and control (CTR) groups. D, However, levels remain elevated in treatment group even at 6 weeks after SWT. E, VEGF protein concentration (given as $\mathrm{pg} / \mathrm{mg}$ protein) showed significant increase in treatment group compared with untreated controls. $* P<.05$.

mobilization, these results indicate that SWT might induce vasculogenesis in ischemic tissue. Nevertheless, homing of EPCs must be demonstrated in future studies.

EPCs are known to be stored in the bone marrow, vascular adventitia, and/or endothelium itself and to circulate in the peripheral blood. ${ }^{14-16}$ However, the phenotypic characterization of EPCs is still a matter of concern. ${ }^{17-19}$ We used a typical endothelial marker (CD31) and a stem cell marker (CD34) to evaluate the effects of SWT on the circulating EPCs. However, future experiments are needed to demonstrate incorporation of bone marrow-derived cells into the vasculature of ischemic muscle after SWT and their exact origin, which we have assumed to be the bone marrow.

EPCs are retained in the bone marrow by SDF-1, which serves as a ligand for their $\mathrm{C}-\mathrm{X}-\mathrm{C}$ chemokine receptor type 4 receptor. Chronic ischemic tissue loses its ability to express chemoattractants for progenitor cells. Application of SWT leads to increased expression of HIF- $1 \alpha$, which is in part responsible for upregulation of SDF-1 and VEGF, which themselves are also increased by SWT in ischemic tissue. Therefore, it could be conceivable that stimulation of HIF- $1 \alpha$ might be upstream of VEGF and SDF-1 elevation. This, however, needs further experimental validation. Obviously, some of the released SDF-1 enters the systemic circulation. Greater SDF-1 serum levels cause desensitization of progenitor cells in bone marrow, thus, increasing their likelihood of mobilization. ${ }^{20}$ SDF-1 released around ischemic vessels enhances tissue-specific adhesion of mobilized progenitor cells. ${ }^{10}$

Additionally, VEGF-A was upregulated in both the treatment and the control group 24 hours after SWT. However, in the treatment group, the VEGF levels remained elevated 6 weeks after treatment. This could be confirmed by the protein level, which was shown by the VEGF enzyme-linked 


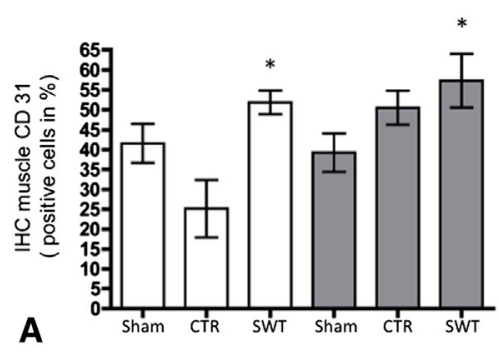

CTR

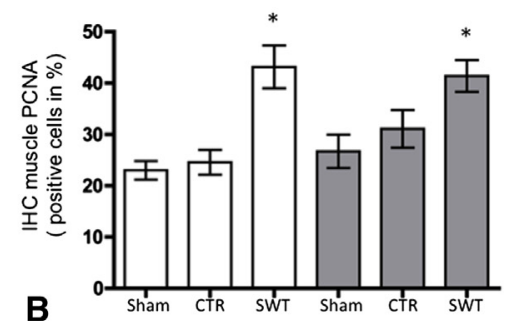

B

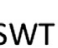

SWT
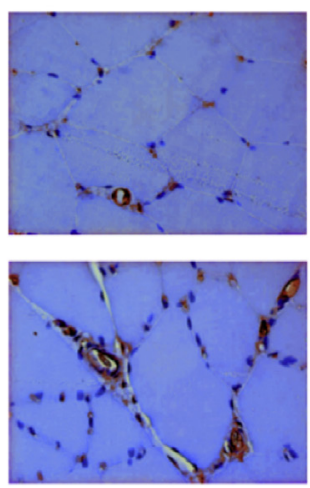

FIGURE 3. Increase of capillary density in treated ischemic muscle. A, Immunohistochemical staining for CD31-positive cells revealed significantly greater numbers of capillaries 24 hours and 6 weeks after shock wave therapy $(S W T)$. Data presented as percentage of total cells per high power field. $\mathrm{B}$, Significantly more proliferating cells found in treatment group, as shown by proliferating cell nuclear antigen (PCNA). In addition to hypothesis of endothelial progenitor recruitment for vasculogenesis, this indicates additional vessel sprouting in parallel. C, Representative views of immunohistochemical (IHC) staining for CD31 (endothelial cells) and PCNA (proliferating cells). Magnification $\times 400$. $* P<.05$. CTR, Control.

immunosorbent assay. VEGF is well known, not only as a main angiogenic growth factor, but also for its major chemoattractive effect toward EPCs, serving as an adjunct to SDF-1. ${ }^{11}$

An interesting observation was that 24 hours after SWT, the mRNA of HIF- $1 \alpha$ and SDF-1 was downregulated in the control groups (ischemia) compared with the sham-operated group. VEGF, however, was upregulated in ischemia, as expected. SWT increased HIF- $1 \alpha$ and SDF-1, which might indicate that the mRNA of these factors are inhibited (eg, by miRNAs) in ischemia and that this inhibition is blunted by SWT. This observation might indicate a new target of SWT and deserves additional investigation in future studies.

Significantly greater numbers of proliferating endothelial cells were found in the treatment group, as shown by PCNA staining. In addition to the hypothesis of endothelial
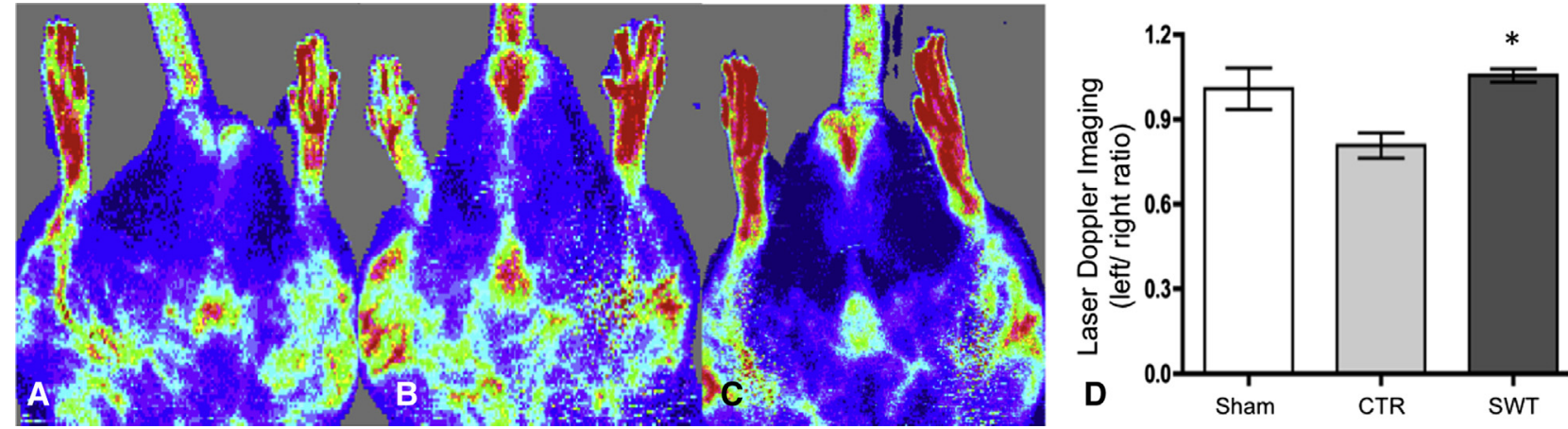

FIGURE 4. Restoration of blood perfusion. Blood perfusion of hind limbs measured by laser Doppler perfusion imaging 6 weeks after treatment. A, Blood perfusion of sham-operated rat; B, Representative view of perfusion in untreated control (CTR); and C, representative view of perfusion of shock wave therapy $(S W T)$ rat. Blood perfusion clearly restored in treatment group. D, Quantification of measurements expressed as ratio of right (operated, ischemic) leg to left (nonoperated, nonischemic) leg revealing significant improvement in treatment group compared with untreated controls. $* P<.05$. 

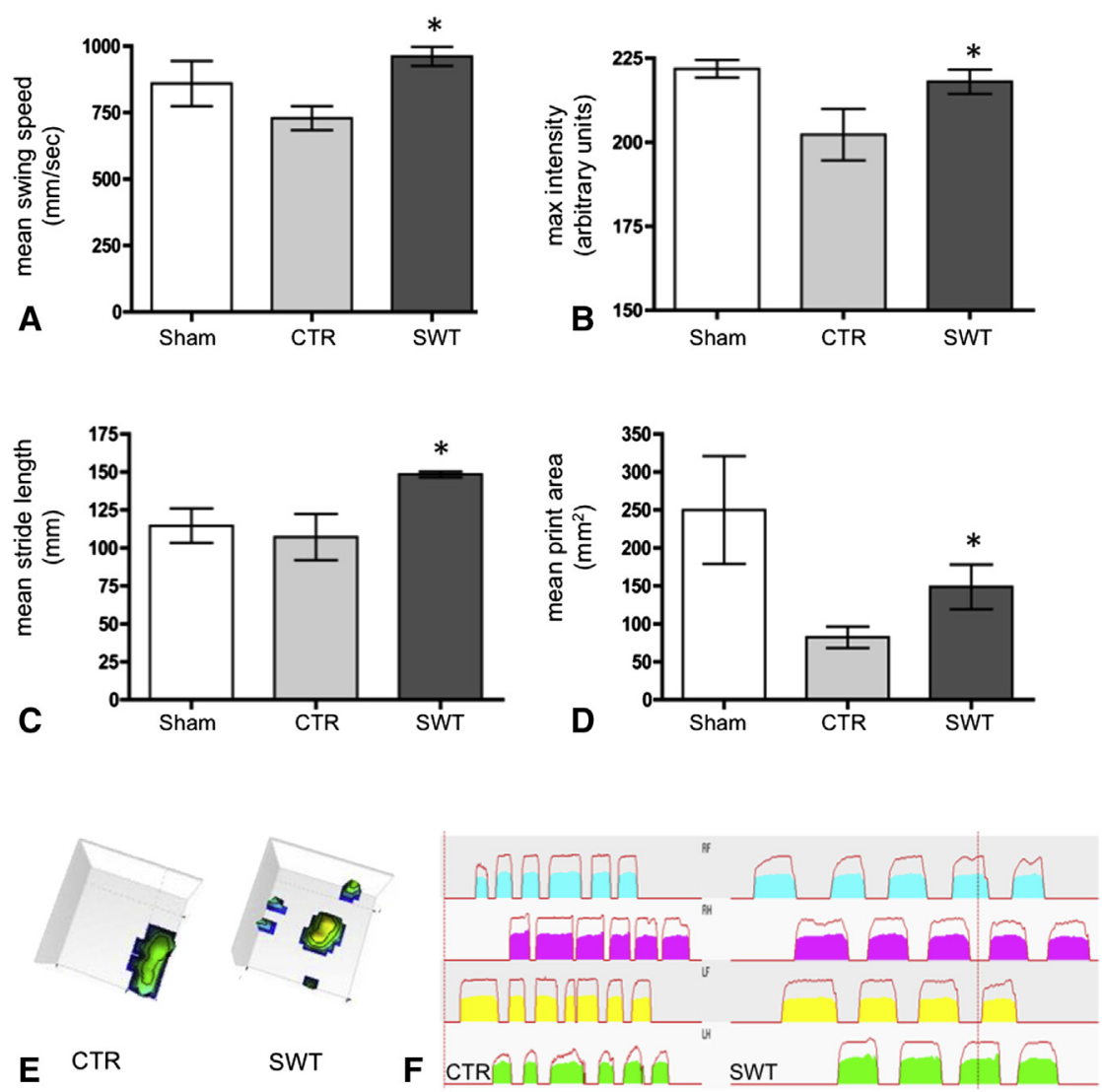

FIGURE 5. Functional recovery of ischemic limbs. Functional assessment performed by catwalk gait analysis 6 weeks after treatment showing restored blood perfusion resulted in recovery of walking pattern in shock wave therapy ( $S W T$ ) group. Significant improvement found in A, swing speed of hind limbs and B, their maximum print intensity. Recovery also seen in C, mean stride length and D, mean print area. E, More physiologic footprint of treatment animal (Right) compared with typically malfunctioning step of control (CTR) animal (Left). F, Walking regularity clearly restored 6 weeks after SWT. $* P<.05$.

progenitor recruitment, this indicates additional induction of local angiogenesis in the ischemic muscle after SWT.

Thus, VEGF serves as the pivotal growth factor for angiogenesis and induces blood vessel formation after experimental myocardial infarction. ${ }^{21}$

According to our morphologic findings of revascularization, laser Doppler perfusion imaging revealed a significantly greater perfusion rate in the treated rats 6 weeks after treatment. The walking analysis was performed to evaluate the functional improvement of the treated limbs. At 6 weeks after SWT, the rats showed a regular walking pattern, although hardly any improvement was found in the control group.

In previous experiments, we have shown improvement in the left ventricular ejection fraction after SWT after myocardial infarction in rats. The results of the present study support these findings and suggest that SWT in ischemic muscle tissue could even serve as an "endogenous cell therapy," although in the present study, EPC mobilization only, and not EPC homing, was shown. A treatment strategy that induces mobilization and homing of endogenous vesselforming EPCs would avoid the numerous side effects associated with any kind of cell therapy. Moreover, shock waves are well known from their use in lithotripsy for more than 30 years to cause no severe side effects. This includes no neovascularization in healthy, nonischemic tissue, such as was shown in an earlier experiment of myocardial infarction in rats. ${ }^{2}$

Showing the same positive effects as endothelial, progenitor, or stem cell treatment, SWT could, therefore, be the superior treatment strategy. It is not only safer, but also easier to handle and much more available and, thereby, more cost-effective.

Additional studies are underway to clarify the exact mechanisms of cell recruitment after SWT. However, our current findings already clearly suggest that SWT could in future not only serve as an adjunct, but even as an alternative to stem cell therapy, in ischemic heart and limb disease.

\section{References}

1. Wang Y, Guo T, Cai HY, Ma TK, Tao SM, Sun S, et al. Cardiac shock wave therapy reduces angina and improves myocardial function in patients with refractory coronary artery disease. Clin Cardiol. 2010;33:693-9.

2. Zimpfer D, Aharinejad S, Holfeld J, Thomas A, Dumfarth J, Rosenhek R, et al. Direct epicardial shock wave therapy improves ventricular function and induces angiogenesis in ischemic heart failure. J Thorac Cardiovasc Surg. 2009;137:963-70. 
3. Ottomann C, Stojadinovic A, Lavin PT, Gannon FH, Heggeness MH, Thiele R, et al. Prospective randomized phase II trial of accelerated reepithelialization of superficial second-degree burn wounds using extracorporeal shock wave therapy. Ann Surg. 2012;255:23-9.

4. Mittermayr R, Hartinger J, Antonic V, Meinl A, Pfeifer S, Stojadinovic A, et al. Extracorporeal shock wave therapy (ESWT) minimizes ischemic tissue necrosis irrespective of application time and promotes tissue revascularization by stimulating angiogenesis. Ann Surg. 2011;253:1024-32.

5. Aicher A, Heeschen C, Sasaki K, Urbich C, Zeiher AM, Dimmeler S. Lowenergy shock wave for enhancing recruitment of endothelial progenitor cells: a new modality to increase efficacy of cell therapy in chronic hind limb ischemia. Circulation. 2006;114:2823-30.

6. Yeh KH, Sheu JJ, Lin YC, Sun CK, Chang LT, Kao YH, et al. Benefit of combined extracorporeal shock wave and bone marrow-derived endothelial progenitor cells in protection against critical limb ischemia in rats. Crit Care Med. 2012;40:169-77.

7. Couffinhal T, Silver M, Zheng LP, Kearney M, Witzenbichler B, Isner JM. Mouse model of angiogenesis. Am J Pathol. 1998;152:1667-79.

8. Hamers FP, Lankhorst AJ, van Laar TJ, Veldhuis WB, Gispen WH. Automated quantitative gait analysis during overground locomotion in the rat: its application to spinal cord contusion and transection injuries. J Neurotrauma. 2001;18:187-201.

9. Koopmans GC, Deumens R, Honig WM, Hamers FP, Steinbusch HW, Joosten EA. The assessment of locomotor function in spinal cord injured rats: the importance of objective analysis of coordination. J Neurotrauma. 2005;22: 214-25.

10. Ceradini DJ, Kulkarni AR, Callaghan MJ, Tepper OM, Bastidas N, Kleinman ME, et al. Progenitor cell trafficking is regulated by hypoxic gradients through HIF-1 induction of SDF-1. Nat Med. 2004;10:858-64.

11. Asahara T, Takahashi T, Masuda H, Kalka C, Chen D, Iwaguro H, et al. VEGF contributes to postnatal neovascularization by mobilizing bone marrow-derived endothelial progenitor cells. EMBO J. 1999;18:3964-72.
12. Tanaka E, Hattan N, Ando K, Ueno H, Sugio Y, Mohammed MU, et al. Amelioration of microvascular myocardial ischemia by gene transfer of vascular endothelial growth factor in rabbits. J Thorac Cardiovasc Surg. 2000;120:720-8.

13. Hiesinger W, Frederick JR, Atluri P, McCormick RC, Marotta N, Muenzer JR, et al. Spliced stromal cell-derived factor- $1 \alpha$ analog stimulates endothelial progenitor cell migration and improves cardiac function in a dose-dependent manner after myocardial infarction. J Thorac Cardiovasc Surg. 2010;140:1174-80.

14. Rabelink TJ, de Boer HC, de Koning EJ, van Zonneveld AJ. Endothelial progenitor cells: more than an inflammatory response? Arterioscler Thromb Vasc Biol. 2004;24:834-8.

15. Urbich C, Dimmeler S. Endothelial progenitor cells functional characterization. Trends Cardiovasc Med. 2004;14:318-22.

16. Yoder MC. Is endothelium the origin of endothelial progenitor cells? Arterioscler Thromb Vasc Biol. 2010;30:1094-103.

17. Hagensen MK, Vanhoutte PM, Bentzon JF. Arterial endothelial cells: still the craftsmen of regenerated endothelium. Cardiovasc Res. 2012;95:281-9.

18. Zhang Y, Wong S, Laflèche J, Crowe S, Mesana TG, Suuronen EJ, et al. In vitro functional comparison of therapeutically relevant human vasculogenic progenitor cells used for cardiac cell therapy. J Thorac Cardiovasc Surg. 2010;140: 216-24, 224.e1-4.

19. Suuronen EJ, Price J, Veinot JP, Ascah K, Kapila V, Guo XW, et al. Comparative effects of mesenchymal progenitor cells, endothelial progenitor cells, or their combination on myocardial infarct regeneration and cardiac function. $J$ Thorac Cardiovasc Surg. 2007;134:1249-58.

20. Sweeney E, Lortat-Jacob H, Priestley G, Nakamoto B, Papayannopoulou T. Sulfated polysaccharides increase plasma levels of SDF-1 in monkeys and mice: involvement in mobilization of stem/progenitor cells. Blood. 2002;99:44-51.

21. Ye L, Haider HK, Tan R, Toh W, Law PK, Tan W, et al. Transplantation of nanoparticle transfected skeletal myoblasts overexpressing vascular endothelial growth factor-165 for cardiac repair. Circulation. 2007;116(11 suppl):I113-20. 